\title{
(3Z)-5-Chloro-3-(Hydroxyimino)indolin-2- one attenuates hyperglycemia, increased hepatic glycogen content and hepatic damage induced by malathion acute exposure in rats
}

Edina da Luz Abreu', Anne Suély Pinto Savall', Allyson Ardais Boneberg ${ }^{1}$, Bianca Barreto Martins²,

Vanessa Carratú Gervini ${ }^{2}$, Tuane Bazanella Sampaio ${ }^{3}$, André Ricardo Fajardo ${ }^{4}$, Natália Paroul ${ }^{5}$,

Daniel Henrique Roos $^{1}$ and Simone Pinton ${ }^{1 *}$

\begin{abstract}
Background: Organophosphorus pesticides (OP's) are heavily constituted in agriculture, gardens, home and veterinary and although it is useful, there are concerns about the environment, safety and health of human and animals. In this study, we investigated the effects of a new oxime, (3Z)-5-Chloro-3-(Hydroxyimino)indolin-2-one (OXIME) against the alterations induced by malathion, an OP insecticide, acute exposure on markers of hepatic damage, glucose homeostasis, oxidative stress in rats cholinesterase (ChE) activity in rats.
\end{abstract}

Methods: Adult male Wistar rats were divided into four groups: Control; Malathion; OXIME; and Malathion+OXIME. Twelve hours after co-treatment with malathion $(250 \mathrm{mg} / \mathrm{kg}$, i.p.) and/or OXIME $(50 \mathrm{mg} / \mathrm{kg}$, i.g.), the plasma and liver samples were collected for biochemical analyses.

Results: The OXIME blocked the increase of plasma markers of hepatic function (AST and ALP) and the enzymatic inhibition of catalase and glutathione reductase in the liver of malathion-treated rats. Moreover, the hepatic cholinesterases inhibition induced by malathion acute exposure was suppressed by OXIME treatment. As assessed, a single dose of OXIME lowered the glycemia levels and hepatic glycogen content enhanced by malathion.

Conclusions: This study suggests promise effects of (3Z)-5-Chloro-3-(Hydroxyimino) indolin-2-one against the hyperglycemia and the hepatic damage induced by malathion acute exposure, as well as its use as a ChE activity reactivator.

Keywords: Cholinesterases, Aminotransferases, Antioxidant enzymes, Glucose metabolism, Organophosphate, Oxime

\footnotetext{
* Correspondence: sipinton@gmail.com

${ }^{1}$ Universidade Federal do Pampa (UNIPAMPA) Campus Uruguaiana,

Uruguaiana, RS CEP 97500-970, Brazil

Full list of author information is available at the end of the article
}

(c) The Author(s). 2019 Open Access This article is distributed under the terms of the Creative Commons Attribution 4.0 International License (http://creativecommons.org/licenses/by/4.0/), which permits unrestricted use, distribution, and reproduction in any medium, provided you give appropriate credit to the original author(s) and the source, provide a link to the Creative Commons license, and indicate if changes were made. The Creative Commons Public Domain Dedication waiver (http://creativecommons.org/publicdomain/zero/1.0/) applies to the data made available in this article, unless otherwise stated. 


\section{Introduction}

The organophosphates pesticides (OP) are chemicals compounds widely used in agriculture, gardens, household and veterinary [1]. Among the OP, malathion [S-1,2(bisethoxycarbonyl)ethyl-O,O-dimethyl phosphorodithioate] stands out due to its high toxicity [2, 3]. Malathion is distributed mainly to the liver, kidney, small intestine, urinary tract, and lungs. The bioactivation of malathion is mediated mainly by enzymes of cytochrome P450 in the liver [4], generating the active metabolite malaoxon $[5,6]$.

The OP's are associated with adverse effects on human and animal health [7-9]. Theirs primary mechanism of toxicity involve the inhibition of acetylcholinesterase (AChE) activity. Besides the cholinergic system, the OPexposure can trigger several physiological responses including alterations in the glucose homeostasis [10-13], hyperglycemia $[12,14,15]$ and oxidative stress [16-20]. Further, the exposition to OP alters biochemical parameters of hepatotoxicity $[6,16,21,22]$, indicating the occurrence of liver injury [12, 21, 23].

Glucose homeostasis changes and hepatic damage have been largely investigated and indicate the involvement of additional toxicity pathways of OP. In fact, changes in the glucose homeostasis have been demonstrated both in animals subjected to acute and chronic exposure to OP's [10-13] as in OP-exposed humans [24, 25]. In this way, glycogenolysis, gluconeogenesis, and hypothalamuspituitary-adrenal (HPA) axis seem to be affected by OP exposure resulting in hyperglycemia [12, 14].

In regards to oxidative stress, studies demonstrated that the exposure to OP resulted in increased lipid peroxidation and decreased glutathione levels in liver, kidney, heart, blood and brain structures $[17,18,21]$. In addition, the activities of the antioxidant enzymes glutathione peroxidase (GPx), glutathione reductase (GR), superoxide dismutase (SOD) and catalase (CAT) also were altered by OP in several tissues [16-18].

The standard therapeutic strategy for acute exposure to OP includes the use of anticholinergics (muscarinic receptor antagonists), AChE reactivators drugs (oximes), and diazepam [26]. Oxime derivatives (e.g. pyridinium oximes) have been used as an antidote in the detoxification step. However, there is no compelling evidence about the efficacy of oximes therapies since the results have shown that the success of these therapies depends both oxime and OP structure-activity [26-28].

Based on these findings, new drugs or alternative approaches have been considered for OP poisoning therapy [27, 29]. The (3Z)-5-Chloro-3-(Hydroxyimino)indolin-2one (Fig. 1) (OXIME) is a novel oxime derived from isatin ( $1 H$-indole-2,3-dione). Since isatin and its derivatives show various biological activities $[20,30]$ it is plausible that OXIME might be useful against OP poisoning.

Therefore, the purpose of this study was investigating the effectiveness of a single dose of OXIME against the alterations induced by malathion acute exposure on markers of hepatic damage, glucose homeostasis and oxidative stress in rats. Additionally, we also addressed the ability of the OXIME reactivate the cholinesterase $(\mathrm{ChE})$ activity, reducing the adverse effects of malathion.

\section{Materials and methods}

Drugs and chemicals

Malathion 500 CE (5.0\%) (Biocarb Chemical Industry LTDA, Curitiba, PR, Brazil) was obtained from commercial

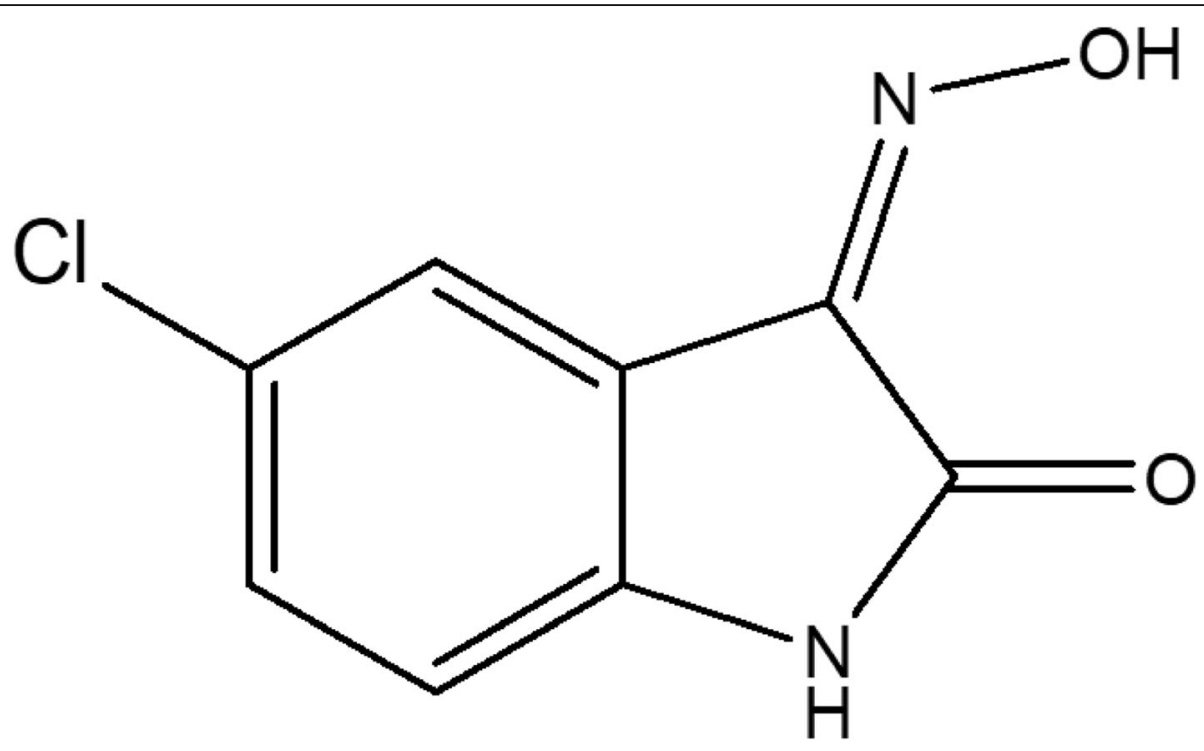

Fig. 1 Chemical structure of (3Z)-5-Chloro-3-(Hydroxyimino)indolin-2-one (OXIME) 
grade. (3Z)-5-Chloro-3-(Hydroxyimino)indolin-2-one (OXIME) was synthesized at the School of Chemistry and Food of Federal University of Rio Grande (FURG), RS, Brazil as described [31]. For this, an equimolar mixture of 5chloroisatin and hydroxylamine chlorhydrate in ethanol was used. The reaction medium was acidified using acetic acid and placed under reflux $\left(135^{\circ} \mathrm{C}\right)$ for $5 \mathrm{~h}$. The reaction was vacuum filtered and the compound was isolated as a golden yellow precipitate. After that, the isolated compound was washed in cold distilled water (F.P. $252-274{ }^{\circ} \mathrm{C}$ ). Analysis of the ${ }^{1} \mathrm{H}{ }^{13} \mathrm{C}$ nuclear magnetic resonance spectroscopy analysis showed that the compound obtained presented analytical and spectroscopic data in full agreement with its assigned structure. The chemical purity of OXIME (99.9\%) was determined by gas chromatographymass spectrometry. All other chemicals were obtained from analytical grade and standard commercial suppliers.

\section{Animals}

The experiments were carried out using male adult Wistar rats $(n=28), 2$ months of age (250-300 g), purchased from Federal University of Santa Maria, RS, Brazil. The animals were provided with food (commercial diet) and water ad libitum and maintained in the animal house at controlled conditions: temperature $\left(22 \pm 2^{\circ} \mathrm{C}\right)$ and $12 \mathrm{~h}$ light-dark cycle (lights on at 7:00 a.m.). All experiments were performed according to the local ethics committee of the Federal University of Pampa, Brazil (CEUA/UNIPAMPA 024/2016). All efforts were made to minimize animals suffering and to reduce the number of animals used in the experiments.

\section{Experimental design}

In order to access the effects of an acute exposure to malathion and the putative beneficial effects of OXIME on markers of hepatic damage, glucose homeostasis, oxidant-antioxidant system and ChE activity, rats were randomized into four groups with seven animals per group:

I. Control - distilled water by intraperitoneal injection (i.p.; $5 \mathrm{~mL} / \mathrm{kg}$ ) plus canola oil by intragastric gavage (i.g.; $3 \mathrm{~mL} / \mathrm{kg}$ );

II. Malathion - malathion $(250 \mathrm{mg} / \mathrm{kg}$; i.p.) plus canola oil (i.g);

III. OXIME - distilled water (i.p.) plus [(3Z)-5-Chloro3-(Hydroxyimino) indolin-2-one] (50 mg/kg; i.g.);

IV. Malathion + OXIME - malathion $(250 \mathrm{mg} / \mathrm{kg}$; i.p.) plus [(3Z)-5-Chloro-3-(Hydroxyimino) indolin-2one] $(50 \mathrm{mg} / \mathrm{kg}$; i.g.);

The malathion dose of $250 \mathrm{mg} / \mathrm{kg}$ was selected based on a previously published study [32], which demonstrated that malathion caused metabolic disorders in rats. The OXIME dose of $50 \mathrm{mg} / \mathrm{kg}$ was established through a pilot study by our research group (data not shown).

Twelve hours after treatment with malathion and/or OXIME and/or vehicles, following overnight fasting, all rats were anesthetized for blood collection by heart puncture. The time to collect of samples (12 h) was based on a pilot study of our research group and other results described [33, 34]. Plasma was extracted by centrifugation at $2500 \mathrm{~g}$ for $10 \mathrm{~min}$ and conserved at $-20^{\circ} \mathrm{C}$ for posterior analyses. In the sequence, the animals were killed and their livers were removed. Except for protein carbonyl content assay and ChE activity, the liver samples were homogenized in $50 \mathrm{mM}$ Tris- $\mathrm{HCl}(\mathrm{pH} 7.4 ; 1$ : $10 \mathrm{w} / \mathrm{v})$ and centrifuged at $2500 \mathrm{~g}$ for $10 \mathrm{~min}$ at $4{ }^{\circ} \mathrm{C}$. The low-speed supernatants $\left(\mathrm{S}_{1}\right)$ were used to the biochemical assays.

\section{Glucose homeostasis evaluation}

Blood glucose levels and hepatic glycogen content were measured as indicators of the glucose homeostasis. Blood glucose levels were established by an enzymatic method based on the oxidase/peroxidase system using a commercial kit (Bioclin, Belo Horizonte, Minas Gerais, Brazil). Blood glucose levels results were expressed in $\mathrm{mg} / \mathrm{dL}$. Hepatic glycogen content was performed according to the method described [35]. Briefly, $0.3 \mathrm{~g}$ of the liver was digested in $3 \mathrm{~mL}$ of $\mathrm{KOH} 30 \%$, incubated for $10 \mathrm{~min}$ at $90^{\circ} \mathrm{C}$. After that, glycogen was precipitated with $2 \mathrm{~mL}$ of ethanol and resuspended in $0.2 \mathrm{~mL} 5 \mathrm{M}$ $\mathrm{HCl}$ and $0.8 \mathrm{~mL}$ distilled water. The glycogen content was measured with iodine reagent at $460 \mathrm{~nm}$ and expressed as \% of hepatic glycogen.

\section{Hepatic function markers}

Plasma samples were used to determine the aspartate aminotransferase (AST), alanine aminotransferase (ALT), alkaline phosphatase (ALP) and lactate dehydrogenase (LDH) activities as a parameter of the hepatic function. The colorimetric method was carried out to measure both AST and ALT activities [36]. Whereas, ALP and LDH activities were accessed using a commercial kit (Bioclin, Belo Horizonte, Minas Gerais, Brazil). The values were expressed as $\mathrm{U} / \mathrm{dL}$.

\section{Oxidative stress markers \\ Thiobarbituric acid reactive species (TBARS) levels}

Hepatic TBARS levels, a measure of lipid peroxidation, were performed using an aliquot $(200 \mu \mathrm{L})$ of $\mathrm{S}_{1}, 500 \mu \mathrm{L}$ thiobarbituric acid $(0.8 \%), 500 \mu \mathrm{L}$ acetic acid buffer, $200 \mu \mathrm{L}$ sodium dodecyl sulfate (SDS, 8.1\%) and $100 \mu \mathrm{L}$ distilled water. The mixture was incubated at $95^{\circ} \mathrm{C}$ for $2 \mathrm{~h}$. The absorbance was measured at $532 \mathrm{~nm}$. The 
results were expressed as nmol $\mathrm{MDA} / \mathrm{mg}$ protein as described [37].

\section{Protein carbonyl content}

Protein carbonyl content in the liver was determined through of the reaction between protein carbonyls and 2,4-dinitrophenylhydrazine forming dinitrophenylhydrazone, a yellow compound [38]. Briefly, hepatic homogenates without centrifugation were diluted 1:10 $(v / v)$ and an aliquot of $1 \mathrm{~mL}$ was added to the reaction mixture containing $200 \mu \mathrm{L}$ of $10 \mathrm{mM}$ dinitrophenylhydrazine (prepared in $2 \mathrm{M} \mathrm{HCl}$ ). All tubes were incubated at room temperature in the dark for $1 \mathrm{~h}$ and shaken with a vortex mixer each $15 \mathrm{~min}$. After that, $500 \mu \mathrm{L}$ of denaturation buffer, $1.5 \mathrm{~mL}$ of ethanol and $1.5 \mathrm{~mL}$ of hexane were added to each tube. The tubes were shaken with a vortex mixer for $40 \mathrm{~s}$ and centrifuged at $3000 \mathrm{~g}$ for $15 \mathrm{~min}$. The supernatants obtained were discarded. The pellets were washed twice with $1 \mathrm{~mL}$ ethanol: ethyl acetate $(1: 1, v / v)$ and resuspended in $1 \mathrm{~mL}$ of denaturation buffer. Absorbance was determined at $370 \mathrm{~nm}$. Data were expressed as nmol carbonyl content/mg protein.

\section{Non-protein sulfhydryl (NPSH) content}

To determine hepatic NPSH content, $S_{1}$ was mixed (1:1) with $10 \%$ trichloroacetic acid. After the centrifugation, the protein pellet was discarded and the free $\mathrm{SH}$-groups were determined in the clear supernatant. An aliquot of supernatant was added in $1 \mathrm{M}$ potassium phosphate buffer $\mathrm{pH}$ 7.4 and $10 \mathrm{mM}$ DTNB (5,5'-dithiobis-2-nitrobenzoic acid). The color reaction was measured at $412 \mathrm{~nm}$. NPSH levels were expressed as nmol NPSH/g tissue [39].

\section{Enzymatic antioxidant defenses}

Catalase (CAT) activity was spectrophotometrically assayed by the method [40], which involves monitoring the consumption of $\mathrm{H}_{2} \mathrm{O}_{2}$ in the $\mathrm{S}_{1}$ at $240 \mathrm{~nm}$. The enzymatic reaction was initiated by adding an aliquot of $40 \mu \mathrm{L}$ of the $S_{1}$ from liver samples and the substrate $\left(\mathrm{H}_{2} \mathrm{O}_{2}\right)$ to a concentration of $0.3 \mathrm{M}$ in a medium containing $50 \mathrm{mM}$ phosphate buffer, $\mathrm{pH}$ 7.0. The enzymatic activity was expressed in Units ( $1 \mathrm{U}$ decomposes $1 \mu \mathrm{mol}$ $\mathrm{H}_{2} \mathrm{O}_{2} / \mathrm{min}$ at $\mathrm{pH} 7$ at $25^{\circ} \mathrm{C}$ )/mg protein.

Glutathione peroxidase (GPx) activity in the liver was measured by the nicotinamide adenine dinucleotide phosphate (NADPH) oxidation rate at $340 \mathrm{~nm}$ using $\mathrm{H}_{2} \mathrm{O}_{2}$ as substrate [41]. The reaction mixture consisted of EDTA, NADPH, GSH, sodium azide, and glutathione reductase (GR). The reaction was initiated by the addition of $\mathrm{H}_{2} \mathrm{O}_{2}$. The disappearance of NADPH at 340 $\mathrm{nm}$ was recorded at room temperature. Enzyme activity was defined as nmol NADPH/min/mg protein.

GR activity in the liver was estimated by the method describe [42]. The reagent mixture was composed of
$150 \mathrm{mM}$ potassium phosphate buffer ( $\mathrm{pH} 7.0$ ), $1.5 \mathrm{mM}$ EDTA, $0.15 \mathrm{mM}$ NADPH. Oxidized glutathione (GSSG) was used as the substrate. GR activity is proportional to $\mathrm{NADPH}$ decay at $340 \mathrm{~nm}$. The enzymatic activity was expressed as nmol $\mathrm{NADPH} / \mathrm{min} / \mathrm{mg}$ protein.

\section{Hepatic cholinesterase (ChE) activity}

Samples of liver were homogenized in $0.25 \mathrm{M}$ sucrose buffer $(1: 10, \mathrm{w} / \mathrm{v})$ and centrifuged at $2400 \mathrm{~g}$ for $15 \mathrm{~min}$ at $4{ }^{\circ} \mathrm{C}$. ChE activity (a mixture of butyrylcholinesterase and AChE) was carried out according to the method describe [43], using acetylthiocholine as substrate. The activity of ChE was spectrophotometrically measured at $412 \mathrm{~nm}$ and expressed as $\mathrm{nmol} / \mathrm{min} / \mathrm{mg}$ protein.

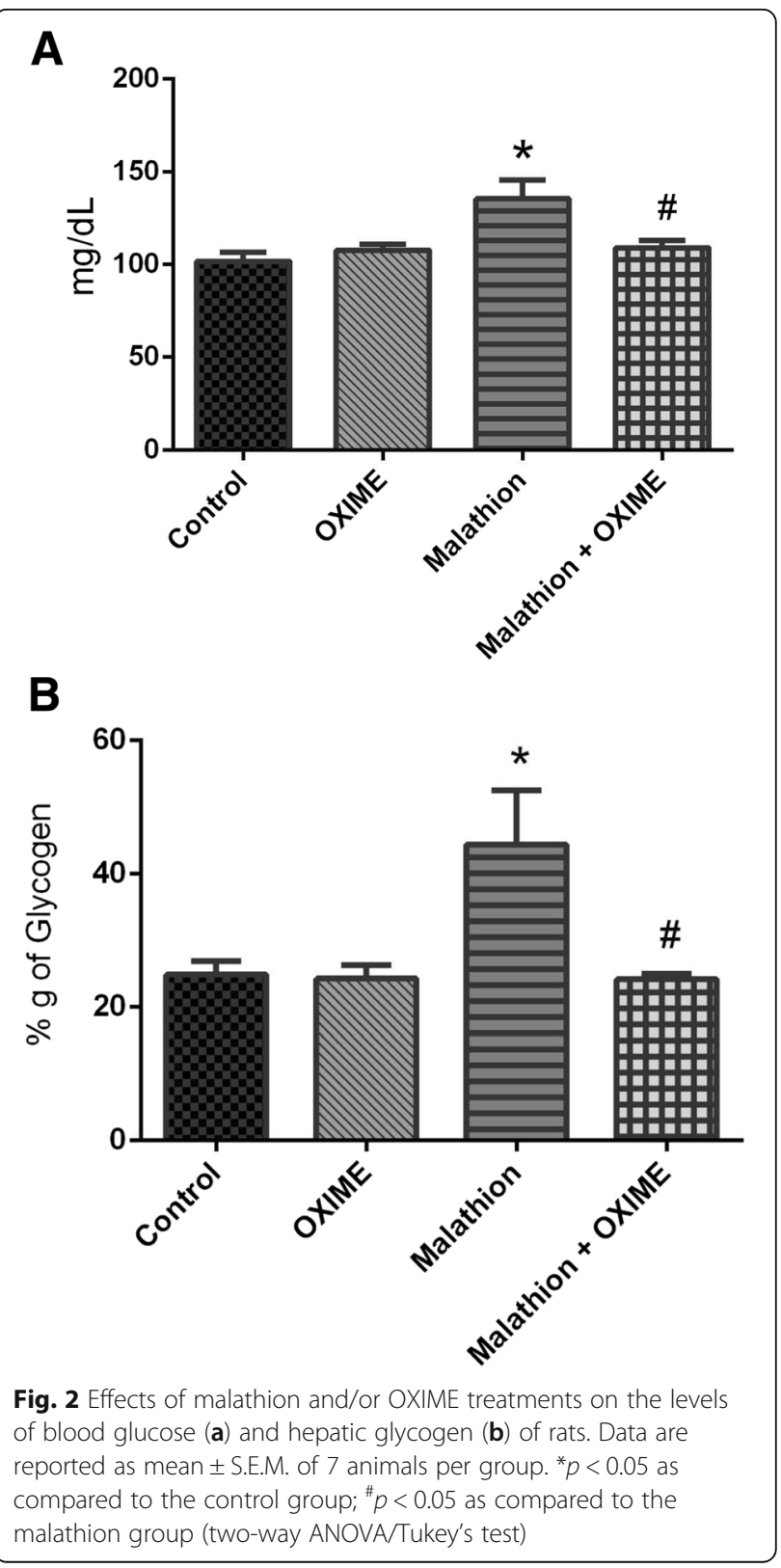


Table 1 Effects of OXIME on ALT, AST, LDH, and ALP activities in the plasma of rats exposed to malathion

\begin{tabular}{lllll}
\hline Group & ALT $(\mathrm{U} / \mathrm{dL})$ & $\mathrm{AST}(\mathrm{U} / \mathrm{dL})$ & $\mathrm{LDH}(\mathrm{U} / \mathrm{dL})$ & $\mathrm{ALP}(\mathrm{U} / \mathrm{dL})$ \\
\hline Control & $43.69 \pm 13.72$ & $106.68 \pm 12.95$ & $393.20 \pm 41.00$ & $60.84 \pm 16.67$ \\
OXIME & $68.95 \pm 21.35$ & $115.78 \pm 7.32$ & $466.00 \pm 59.40$ & $119.76 \pm 25.20$ \\
Malathion & $172.83 \pm 51.03^{*}$ & $201.01 \pm 10.78^{*}$ & $373.60 \pm 77.60$ & $189.53 \pm 39.96^{*}$ \\
Malathion + OXIME & $118.02 \pm 26.95$ & $117.39 \pm 15.58^{\#}$ & $395.40 \pm 107.00$ & $81.50 \pm 20.34^{\#}$ \\
\hline
\end{tabular}

Data are reported as the mean \pm S.E.M. of 7 animals per group and expressed as $\mathrm{U} / \mathrm{dL} .{ }^{*} p<0.05$ as compared to the control group, ${ }^{\#} p<0.05$ as compared to the malathion group (two-way ANOVA/Tukey's multiple range test)

\section{Protein determination}

The protein content was quantified by the Bradford [44] method using Coomassie blue. The mixture was incubated at room temperature for $10 \mathrm{~min}$ and the developed color was spectrophotometrically determined at $595 \mathrm{~nm}$. Bovine serum albumin $(1 \mathrm{mg} / \mathrm{mL})$ was used as the standard.

\section{Statistical analysis}

The normal distribution of the data was tested with D'Agostino and Pearson normality test. Statistical analysis was performed using a two-way analysis of variance (ANOVA) followed by the Tukey's multiple range test when appropriated (GraphPad Prism 6 software, San Diego, CA, USA). Data were expressed as the mean \pm standard error of mean (S.E.M.) of 7 animals/group. A value of $p<0.05$ was considered significant.

\section{Results}

\section{Glucose homeostasis determination}

Blood glucose levels were substantially increased by malathion (around 35\%) as compared to control group $\left(\mathrm{F}_{1,24}=6.36, p=0.0187\right)$, while that a single dose of OXIME prevented the hyperglycemia caused by malathion in rats $(p=0.0355)$ (Fig. 2a). Furthermore, two-way ANOVA of hepatic glycogen data showed a significant main effect of the malathion $\left(\mathrm{F}_{1,24}=5.26, p=0.0309\right)$ (Fig. 2b). Malathion significantly raised the glycogen contents in the liver of rats $(p=0.0174$, around $77 \%$ when compared to control group) and the OXIME was able to block this effect $(p=0.0134$, when compared to malathion group) (Fig. 2b).

\section{Hepatic function markers}

Two-way ANOVA revealed a significant increase in ALT, AST and ALP activities in the plasma of rats exposed to malathion when compared to those of the control group (ALT $\left[\mathrm{F}_{1,24}=7.27, p=0.0126\right]$; AST $\left[\mathrm{F}_{1,24}=14.79, p=0.0008\right]$; ALP $\left.\left[\mathrm{F}_{1,24}=9.52, p=0.0051\right]\right)$ (Table 1$)$. Importantly, OXIME treatment was effective in reversing the AST $(p=0.0004)$ and ALP $(p=0.0438)$ activities increased by malathion, but it was not effective to restore the ALT activity in the plasma of rats exposed to malathion (Table 1 ). The LDH activity was not altered by the malathion and/or OXIME treatments.

\section{Oxidative stress markers}

As shown in the Table 2, malathion and/or OXIME treatments caused alteration neither in the TBARS $\left(\mathrm{F}_{1,24}=0.0346, p=0.8539\right)$ nor in protein carbonyl levels $\left(\mathrm{F}_{1,24}=0.3150, p=0.8798\right)$. In addition, there was no significant difference in the NPSH levels among groups $\left(\mathrm{F}_{1,24}=0.8783, p=0.3580\right)$ (Table 2$)$.

\section{Enzymatic antioxidant defenses}

Two-way ANOVA of CAT activity demonstrated a significant malathion $\times$ OXIME interaction $\left(\mathrm{F}_{1,24}=7.58\right.$, $p=0.0111$ ) in liver of rats. As shown in the Fig. 3a, acute exposure to malathion decreased the CAT activity (around 60\%) in the liver, which were protected by the OXIME treatment $(p=0.0495)$. However, there was no significant difference in the GPx activity among groups in liver of rats (Fig. 3b) $\left(\mathrm{F}_{1,24}=0.3327, p=0.5695\right)$. Moreover, a significant difference was founded in GR activity in the liver of rats $\left(F_{1,24}=5.22, p=0.0315\right)$. Acute exposure to malathion decreased the GR activity (around $36 \%)$, which were protected by the OXIME treatment $(p=0.0067)$ (Fig. 3c).

\section{Hepatic ChE activity}

Data from hepatic ChE activity demonstrated a significant malathion $\times$ OXIME interaction $\left(\mathrm{F}_{1,24}=11.59\right.$, $p=0.0023$ ). Tukey's post hoc test comparisons revealed that the malathion inhibited the ChE activity in the liver of rats when compared to those of the control group (around 63\%). Moreover, a single dose of OXIME blocked the malathion-induced ChE inhibition $(p=0.0252)$ (Fig. 4).

Table 2 Effects of OXIME on TBARS, protein carbonyl and NPSH levels in the liver of rats exposed to malathion

\begin{tabular}{llll}
\hline Group & TBARS & Protein Carbonyl & NPSH \\
\hline Control & $12.99 \pm 1.46$ & $10.41 \pm 0.32$ & $1.31 \pm 0.063$ \\
Malathion & $12.38 \pm 0.67$ & $9.39 \pm 0.61$ & $1.36 \pm 0.057$ \\
OXIME & $14.45 \pm 1.41$ & $10.12 \pm 0.45$ & $1.23 \pm 0.061$ \\
Malathion + OXIME & $13.40 \pm 1.02$ & $9.58 \pm 0.22$ & $1.40 \pm 0.072$ \\
\hline
\end{tabular}

Data are reported as the mean \pm S.E.M. of 7 animals per group and expressed as $\mathrm{nmol} \mathrm{MDA} / \mathrm{mg}$ protein, $\mathrm{nmol}$ carbonyl content/mg protein and $\mathrm{nmol} \mathrm{NPSH} /$ $\mathrm{g}$ tissue, respectively (two-way ANOVA) 


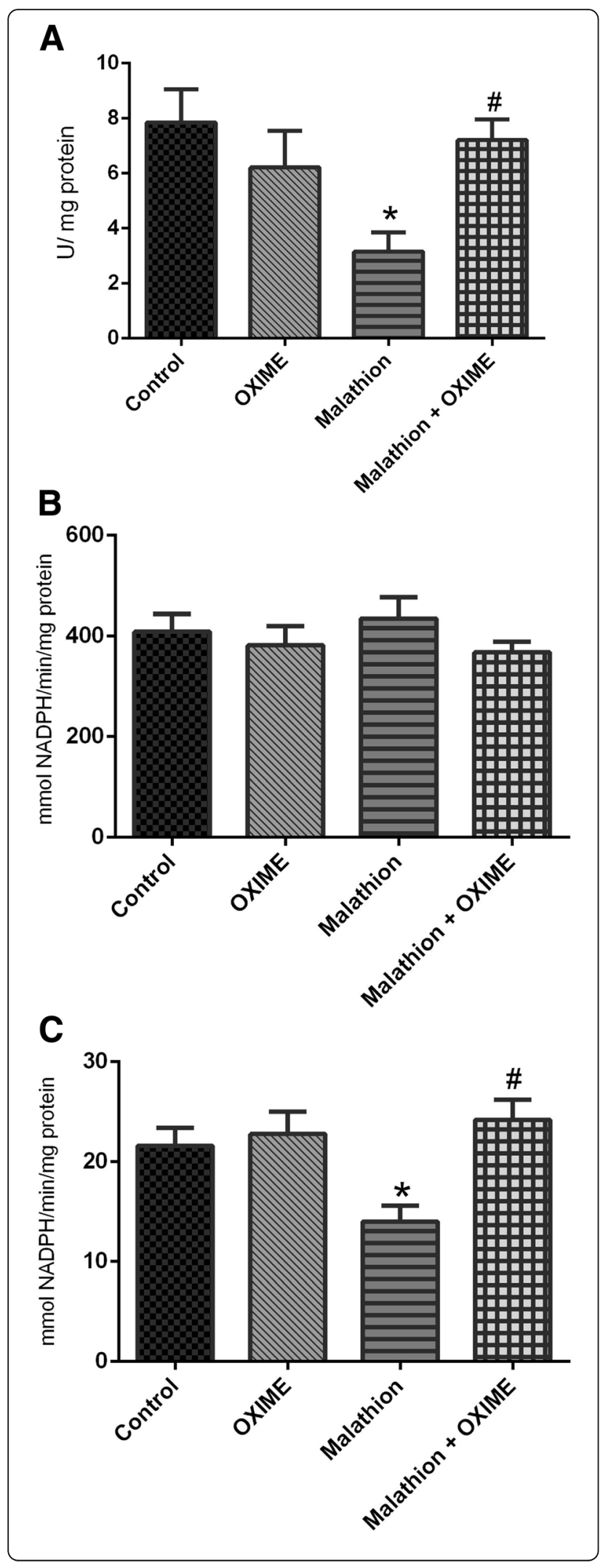

Fig. 3 Effects of malathion and/or OXIME treatments on the catalase (a), glutathione peroxidase (b) and glutathione reductase (c) activities in the liver of rats. Data are reported as mean \pm S.E.M. of 7 animals per group. ${ }^{*} p<0.05$ as compared to the control group; ${ }^{\#} p<0.05$, as compared to the malathion group (two-way ANOVA/Tukey's test)

\section{Discussion}

The present findings demonstrate the beneficial effects of OXIME against to toxicity induced by malathion acute exposure in rats. A single dose oral of OXIME demonstrated a hypoglycemic action and was effective in reducing the increase of the hepatic glycogen content caused by malathion. Concerning the hepatoprotective analysis, the OXIME blocked the increase of the AST and ALP activities in the plasma and the inhibition of the CAT and GR activities in the liver of malathiontreated rats. Importantly, the hepatic ChE inhibition induced by malathion acute exposure was prevented by OXIME treatment.

The long application of OP in agricultural programs was accompanied by a potentially hazardous impact on humans, animals, plants, and the environment (water, air, soil, and food) and causes severe acute and chronic poisoning [45]. In fact, the toxicity of OP results in adverse effects on many organs and systems such as the liver, kidney, nervous system, immune system, and reproductive system [46].

Among the metabolic disorders induced by OP, the alterations in the glucose homeostasis have been highlighted [11, 12, 24, 25, 47]. In the present study, malathion elevated the blood glucose levels of the rats and this alteration was suppressed by the OXIME treatment. Indeed, it was demonstrated that a single dose of malathion [11, 34], as well as other Ops $[14,15,33]$, is associated with increased blood glucose levels in rats. Studies suggest that the hyperglycemic effect of malathion is linked to stimulation of glycogenolysis, gluconeogenesis pathways and insulin resistance [22, 48].

Based on the stimulation of glycogenolysis and gluconeogenesis pathways, we expected a decrease in hepatic glycogen levels by malathion [22, 34]. However, we also observed an increase in the hepatic glycogen levels after the malathion acute exposure, similar results have been reported in rats after acute administration of malathion [49] and chlorpyrifos [50]. Reported [51] that the increase of glycogen levels in the liver is due to stimulation of the glycogen synthetase activity, a key enzyme of glycogenesis. The treatment with a single dose of OXIME was also able to prevent the increase in the hepatic glycogen levels of the rats exposed to malathion.

The liver is one of the main target organs of the malathion toxicity. This OP causes degenerative changes and disrupts the hepatic architecture [23]. Hepatocellular 


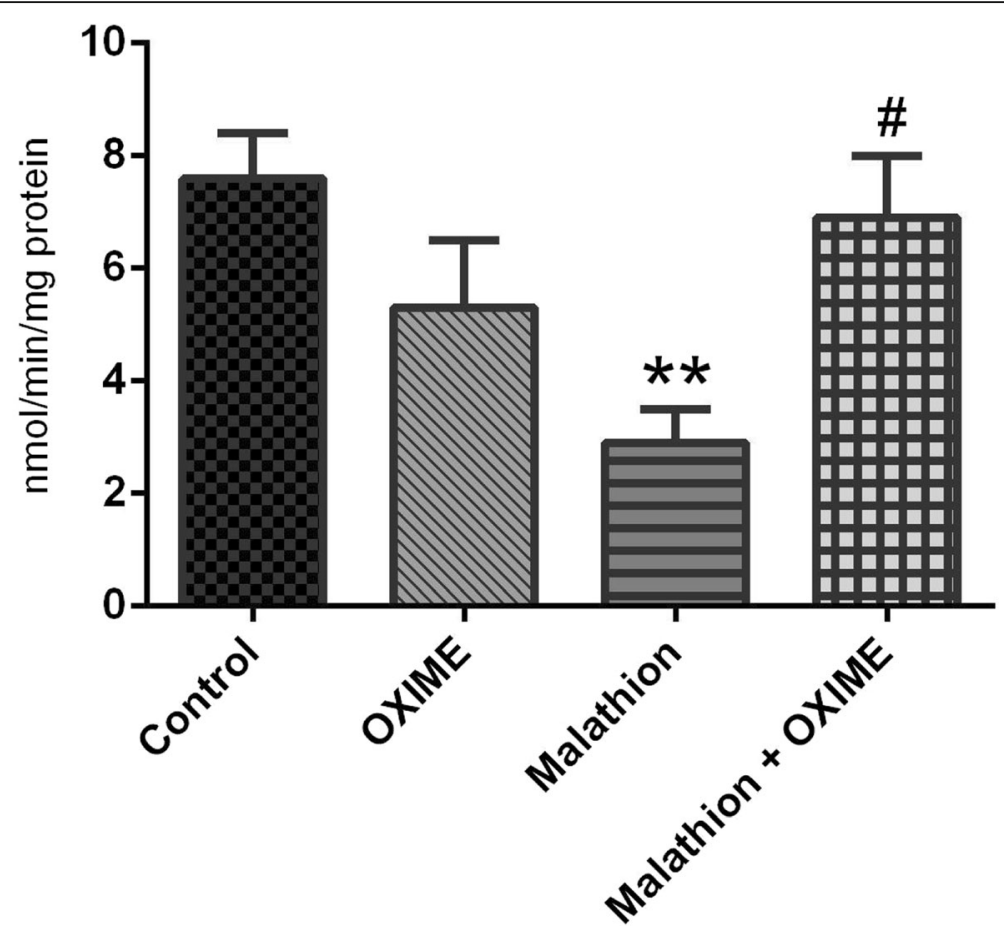

Fig. 4 Effects of malathion and/or OXIME treatments on the hepatic ChE activity of rats. Data are reported as mean \pm S.E.M. of 7 animals per group. ${ }^{* *} p<0.01$ as compared to the control group; ${ }^{*} p<0.05$ as compared to the malathion group (two-way ANOVA/Tukey's test)

necrosis is commonly investigated through the determination of plasma activities of aminotransferases AST and ALT, that are localized in the hepatocytes [52]. In this way, our results corroborate with the literature that show increased levels of AST, ALT, and ALP activities after malathion exposure [16, 51]. In addition, we demonstrated that a single dose of OXIME modulated the activities of AST and ALP, evidencing its - at least in part - hepatoprotective effect.

Surprisingly, our data pointed out no change in the levels of TBARS, NPSH and protein carbonyl in the liver of rats exposed to malathion. Although the oxidative stress is an important component to the mechanism of malathion toxicity $[1,17,53]$, it should be noted that probably the schedule of protocol exposure was the accountable for the lack of alteration in these parameters.

On the other hand, the malathion acute exposure induced a decrease in the GR and CAT activities in the liver, which was suppressed by a single dose of OXIME. Glutathione system represents the main antioxidant defense. Glutathione has a crucial role in cellular signaling and antioxidant defenses either by reacting directly with reactive oxygen or nitrogen species. In concert with its dependent enzymes, denoted as the glutathione system, glutathione is responsible for the detoxification of reactive oxygen and nitrogen species (ROS/RNS) and electrophiles produced by xenobiotics [54].
Currently, the treatment with oximes is established for malathion poisoning. However, the oximes clinically available display many side effects, such as low penetration into the blood-brain barrier and inefficient nucleophilic action [55]. In this context, there is a clear demand for new reactivators of malathion-inhibited ChE activity with a higher efficacy than those available. Of note, the OXIME tested in the present study showed a remarkable effect on the ChE activity inhibition caused by malathion acute exposure, indicating its potential as a $\mathrm{ChE}$ activity reactivator in the malathion poisoning. Finally, the inhibition of the $\mathrm{ChE}$ is of marked interest in OP toxicity, because it may be the route of activation of the HPA axis and consequently to stimulate gluconeogenesis [14].

\section{Conclusion}

In summary, acute exposure to malathion induced changes in the glycemia and glycogen metabolism, hepatotoxicity, reduced activities of enzymatic antioxidant defenses and $\mathrm{ChE}$ in the liver. Importantly, a single dose of (3Z)-5Chloro-3-(Hydroxyimino)indolin-2-one attenuated the malathion-induced toxicity in rats. Malathion exposure has been associated with metabolic disorders, thus, this study suggests promise effects of (3Z)-5-Chloro-3-(Hydroxyimino) indolin-2-one against the hyperglycemia and the hepatic damage induced by malathion acute exposure, as well as its use as a ChE activity reactivator. However, more studies are necessary to elucidate its mechanisms of action. 


\section{Abbreviations}

AChE: Acetylcholinesterase; ALP: Phosphatase alkaline; ALT: Alanine aminotransferase; ANOVA: Analysis of Variance; ANVISA: National Health Surveillance Agency; AST: Aspartate aminotransferase; CAT: Catalase; CEUA: Ethics Committee Use Animals of UNIPAMPA; ChE: Cholinesterase; CNS: Central Nervous System; DTNB: 5,5'-dithiobis-2-nitrobenzoic acid; EDTA: Ethylenediamine tetra acetic acid; GPx: Glutathione Peroxidase; GR: Glutathione Reductase; GSSG: Oxidized glutathione; HPA: Hypothalamuspituitary-adrenal; i.g: Intragastric; i.p: Intraperitoneal; LDH: Lactate dehydrogenase; MAPA: Ministry of Agriculture Livestock and Food Supply; NADPH: Nicotinamide adenine dinucleotide phosphate; NPSH: Non-protein thieves.; OP: Organophosphorus.; TBARS: Thiobarbituric acid reactive species

\section{Acknowledgements}

CNPq, FAPERGS and UNIPAMPA. Moreover, this study was financed in part by the Coordenação de Aperfeiçoamento de Pessoal de Nível Superior Brasil (CAPES). We would like to thank BIOCLIN for donating.

\section{Authors' contributions}

ELA was a major contributor in writing the manuscript, analyzed and interpreted data; ASPS and AAB contributed to animal experiments; BBM and CVG, in the synthesis and characterization of oxime; TBS, ARF, NP and DHR, in the review of the manuscript; SP analyzed and interpreted data. All authors contributed to the planning of experimental protocol, read and approved the final manuscript.

\section{Funding}

This work was supported by the Grants from the FAPERGS (PRONUPEQ, \# 16/2551-0000)

\section{Availability of data and materials}

The datasets used and/or analysed during the current study are available from the corresponding author on reasonable request.

\section{Ethics approval and consent to participate}

All experiments were performed according to the local ethics committee of the Federal University of Pampa, Brazil (CEUA/UNIPAMPA 024/2016). All efforts were made to minimize animals suffering and to reduce the number of animals used in the experiments.

\section{Consent for publication}

Not applicable.

\section{Competing interests}

The authors declare that they have no competing interests.

\section{Author details}

'Universidade Federal do Pampa (UNIPAMPA) Campus Uruguaiana, Uruguaiana, RS CEP 97500-970, Brazil. ${ }^{2}$ Universidade Federal do Rio Grande Campus Carreiros, Rio Grande, RS CEP 96201-900, Brazil. Instituto Federal de Educação, Ciência e Tecnologia Farroupilha - Campus Santo Ângelo, Santo Ângelo, RS CEP 98806-700, Brazil. ${ }^{4}$ Universidade Federal de Pelotas (UFPel) Campus Capão do Leão s/n, Pelotas, RS CEP 96010-900, Brazil. ${ }^{5}$ Universidade Regional Integrada (URI), Campus Erechim, Erechim, RS CEP 99709-910, Brazil.

Received: 1 March 2019 Accepted: 28 June 2019

Published online: 05 September 2019

\section{References}

1. Ullah, et al. Malathion induced oxidative stress leads to histopathological and biochemical toxicity in the liver of rohu (Labeo rohita, Hamilton) at acute concentration. Ecotoxicol Environ Saf. 2018;161:270-80. https://doi. org/10.1016/j.ecoenv.2018.06.002.

2. Rebechi, et al. Low malathion concentrations influence metabolism in Chironumus sancticaroli (Diptera, Chironomidae) in acute and toxicity chronic tests. Rev Bras Entomol. 2014;58:296-301. https://doi.org/10.1590/ S0085-56262014000300012

3. Čolović, et al. Acetylcholinesterase Inhibitors: Pharmacology and Toxicology. Neuropharm. 2013;11:315-35. https:/doi.org/10.2174/1570159X11311030006.
4. Mutch E, Williams FM. Diazinon, chlorpyriphos and parathion are metabolized by multiple cytochrome P450 in human liver. Toxicology. 2007; 22:22-32. https://doi.org/10.1016/j.tox.2006.04.024.

5. Huang, et al. Functional characterization of NADPH-cytochrome P450 reductase from Bactrocera dorsalis: Possible involvement in susceptibility to malathion. Sci Rep. 2015;18:1-12. https://doi.org/10.1038/srep18394.

6. Selmi, et al. Malathion, an organophosphate insecticide, provokes metabolic, histopathologic and molecular disorders in liver and kidney in prepubertal male mice. Toxicol Rep. 2018;5:189-95. https://doi.org/10.1016/j.toxrep.2017.12.021.

7. Devault, et al. Exposure of an urban population to pesticides assessed by wastewater-based epidemiology in a Caribbean island. Sci Total Environ. 2018;644:129-36. https://doi.org/10.1016/j.scitotenv.2018.06.250.

8. Ferré, et al. Reference values for acetyl and butyrycholinesterase is catle under actual management conditions, hepatic and renal by fuction by application of chlorpyrifos. J Environ Sci Health. 2018;53:191-8. https://doi. org/10.1080/036012342017.1405622.

9. Strobel, et al. Organophosphate esters in East Greenland polar bears and ringed seals: Adipose tissue concentrations and in vitro depletion and metabolite formation. Chemos. 2018;196:240-50. https://doi.org/10.1016/j. chemosphere.2017.12.181.

10. Kamath, et al. Altered glucose homeostasis and oxidative impairment in pancreas of rats subjected to dimethoate intoxication. Toxicology. 2007;231: 137-46. https://doi.org/10.1016/.tox.2006.11.072.

11. Lasram, et al. Effect of short-time malathion administration on glucose homeostasis in Wistar rats. Pestic Biochem Physiol. 2008;92:114-9. https://doi.org/10.1016/j.pestbp.2008.06.006.

12. Acker $\mathrm{Cl}$, Nogueira CW. Diphenyl diselenide protects against metabolic disorders induced by Acephate acute exposure in rats. Environ Toxicol. 2012;29:665-71. https://doi.org/10.1002/tox.21793.

13. Everett CJ, Matheson EM. Biomarkers of pesticide exposure and diabetes in the national health and nutrition survey conducted in 1999-2004. Environ Int. 2010;36:398-401. https://doi.org/10.1016/j.envint.2010.02.010.

14. Joshi AKR, Rajini PS. Reversible hyperglycemia in rats following acute exposure to acephate, an organophosphorus insecticide: role of gluconeogenesis. Toxicology. 2009;257:40-5. https://doi.org/10.1016/j.tox.2008.12.006.

15. Joshi AKR, Rajini PS. Hyperglycemic and stressogenic effects of monocrotophos in rats: Evidence for the involvement of acetylcholinesterase inhibition. Exp Toxicol Pathol. 2012;64:115-20. https://doi.org/10.1016/j.etp.2010.07.003.

16. Abdel-Salam, et al. Nitric oxide synthase inhibitors protect against brain and liver damage caused by acute malathion intoxication. Asian Pac J Trop Med. 2017;10:773-86. https://doi.org/10.1016/j.apjtm.2017.07.018.

17. Akbel, et al. The subchronic exposure to malathion, an organophosphate pesticide, causes lipid peroxidation, oxidative stress, and tissue damage in rats: the protective role of resveratrol. Toxicol Res. 2018;7:503-12. https://doi. org/10.1039/C8TX00030A.

18. Karimani, et al. Protective effects of glycyrrhizin on biochemical, hematological and oxidative stress levels induced by subchronic diazinones in male Wistar rats. Drug Chem Toxicol. 2019;42:300-8. https://doi.org/10.1 080/01480545.2018.1497053.

19. Abdel-Daim, et al. Hepatorenal protective effects of taurine and $\mathrm{N}$ acetylcysteine against lesions induced by fipronil: the antioxidant status and apoptic markers expression in rats. Sci Total Environ. 2019;650:2063-73. https://doi.org/10.1016/j.scitotenv.2018.09.313.

20. Abdollahzadeh et al. Attenuation of organ toxicity by nanomicles containing curcuminoids: Comparison of protective effects on oxidative damage in diazinone-induced tissues. Basic Med. Sci. 2019;22:17-24. https:// doi.org/10.22038/JJBMS.2018.23229.5874

21. Lasram et al. Changes in glucose metabolism and reversion of genes expression in the liver of insulin-resistant rats exposed to malathion. The protective effects of N-acetylcysteine. Gen. Comp. Endoc. 2015;215:88-97. https://doi.org/10.1016/j.ygcen.2014.10.002.

22. Xu et al. Metabolomic analysis for combined hepatotoxicity of chlorpyrifos and cadmium in rats. Toxicol. 2017;384:50-58. https://doi.org/10.1016/j.tox.2 017.04.008.

23. Panda, et al. Glycemic Status in Organophosphorus Poisoning. J Nepal Health Res Counc. 2015;13:214-9 http://dx.doi.org/27005715.

24. Velmurugan et al. Microbial degradation of the intestine of organophosphate insecticides induces glucose intolerance via gluconeogenesis. Gen. Biol. 2017;1:18-28 https://doi.org/10.1186/s13059016-1134-6. 
25. Jokanović M, Prostran M. Pyridinium oximes as cholinesterase reuptake inhibitors. Structure-activity relationship and efficacy in the treatment of poisonings with organophosphorus compounds. Curr. Med. Chem. 2009;16: 2177-2188. https://doi.org/10.2174/092986709788612729.

26. Antonijevic et al. Therapeutic and reactive efficacy of oximes K027 and K203 against a direct acetylcholinesterase inhibitor. NeuroTox. 2016;55:33-39. https://doi.org/10.1016/j.neuro.2016.05.006.

27. Antonijevic B, Stojiljkovic MP. Unequal Efficacy of Pyridinium Oximes in Acute Organophosphate Poisoning. Clin. Med. Res. 2007;5:71-82. https:/doi. org/10.3121/cmr.2007.701.

28. Lorke DE, Petroianu GA. Reversible cholinesterase inhibitors as pretreatment for exposure to organophosphates. A review. J. Appl. Toxicol. 2018;1-16. https://doi.org/10.1002/jat.3662.

29. Varun et al. Isatin and its derivatives: a survey of syntheses, reactions and recent applications. Med. Chem. Comm. 2019;10:351-358. https://doi.org/1 0.1039/C8MD00585K

30. Medvedev, et al. Biological targets for isatin and its analogues: Implications for therapy. Biologics. 2007;1:151-62.

31. Martins et al. IUCrData, 1. 2016;x161506. doi: https://doi.org/10.1107/ S2414314616015066

32. Maris, et al. Gender effects of acute malathion or zinc exposure on the antioxidant response of rat hippocampus and cerebral cortex. Basic Clin Pharmacol Toxicol. 2010;107:965-70. https://doi.org/10.1111/j.1742-7843.2010.00614x.

33. Acker $\mathrm{Cl}$, Nogueira CW. Chlorpyrifos acute exposure induces hyperglycemia and hyperlipidemia in rats. Chemosphere. 2012;89:602-8. https://doi.org/1 0.1016/j.chemosphere.2012.05.05

34. Lasram, et al. Metabolic disorders of acute exposure to malathion in adult Wistar rats. J Hazard Mater. 2009;163:1052-5. https://doi.org/10.1016/j. jhazmat.2008.07.059.

35. Krisman C. A method for the colorimetric estimation of glycogen with iodine. Anal Biochem. 1962:4:17-23. https://doi.org/10.1016/0003-2697(62 )90014-3.

36. Reitman S, Frankel S. A colorimetric method for the determination of serum glutamic oxalacetic and glutamic pyruvic transaminases. Am J Clin Pathol. 1957;28:56-63. https://doi.org/10.1093/ajcp/28.1.56.

37. Ohkawa, et al. Assay for lipid peroxides in animal tissues by thiobarbituric acid reaction. Anal Biochem. 1979;95:351-8. https://doi.org/10.1016/0003-26 97(79)90738-3.

38. Reznick AZ, Packer L. Oxidative damage to proteins: spectrophotometric method for carbonyl assay method for carbonyl assay. Methods Enzymol. 1995;233:357-63. https://doi.org/10.1016/S0076-6879(94)33041-7.

39. Ellman GL. Tissue sulfhydryl groups. Arch Biochem Biophys. 1959;82:70-7. https://doi.org/10.1016/0003-9861(59)90090-6.

40. Aebi H. Catalase in vitro. Methotds Enzymol. 1984;105:121-6. https://doi. org/10.1016/S0076-6879(84)05016-3

41. Wendel A. Glutathione Peroxidase. Methods Enzymol. 1981;77:325-33. https://doi.org/10.1016/S0076-6879(85)13063-6.

42. Carlberg I, Mannervik B. Glutathione Reductase. Methods Enzymol. 1985;113: 484-90. https://doi.org/10.1016/S0076-6879(85)13062-4.

43. Ellman, et al. A new and rapid colorimetric determination of acetylcholinesterase activity. Biochem Pharmac. 1961;7:88-95. https://doi. org/10.1016/0006-2952(61)90145-9.

44. Bradford MM. A rapid and sensitive method for the quantitation of microgram quantities of protein utilizing the principles of protein-dye binding. Anal Biochem. 1976;72:248-54. https://doi.org/10.1016/0003-26 97(76)90527-3

45. Baiomy, et al. Protective effect of ginger and zinc chloride mixture on the liver and kidney alterations induced by malathion toxicity. Int J Immunopathol Pharmacol. 2015;28:122-7. https://doi.org/10.1177/0394632 015572083.

46. Mansour SA, Mossa AH. Oxidative damage, biochemical and histopathological alterations in rats exposed to chlorpyrifos and the antioxidant role of zinc. Pestic Biochem Physiol. 2010;96:14-23. https://doi. org/10.1016/j.pestbp.2009.08.008.

47. Ramirez-Vargas, et al. Effects of exposure to malathion on blood glucose concentration: a meta-analysis. Review article. Environ Sci Pollut Res Int. 2018;25:3233-42. https://doi.org/10.1007/s11356-017-0890-5.

48. Abdollahim, et al. Hyperglycemia associated with increased hepatic glycogen phosphorylase and phosphoenolpyruvate carboxykinase in rats following subchronic exposure to malathion. Comp Biochem Physiol. 2004; 137:343-7. https://doi.org/10.1016/j.cca.2004.03.009.
49. Gupta PK. Malathion induced biochemical changes in rat. Acta Pharmacol Toxicol. 1974;35:191-4. https://doi.org/10.1111/j.1600-0773.1974.tb00738.x.

50. Acker, et al. Diphenyl diselenide attenuates hepatic and hematologic toxicity induced by chlorpyrifos acute exposure in rats. Environ Sci Pollut Res. 2012;19:3481-90. https://doi.org/10.1007/s11356-012-0882-4.

51. Rezg, et al. Biochemical evaluation of hepatic damage in subchronic exposure to malathion in rats: effect on superoxide dismutase and catalase activities using native PAGE. Biol. 2008;331:655-62. https://doi.org/10.1016/j. crvi.2008.06.004

52. Sookoian S, Pirola CJ. Liver enzymes, metabolomics and genome-wide association studies: From systems biology to the personalized medicine. World J Gastroenterol. 2018;21:711-25. https://doi.org/10.3748/wjg.v21.i3.711.

53. Moore, et al. Malathion-induced oxidative stress, cytotoxicity, and genotoxicity in human liver carcinoma (HepG2) cells. Environ Toxicol. 2010; 25:221-6. https://doi.org/10.1002/tox.20492.

54. Morris, et al. The glutathione system: a new drug target in neuroimmune disorders. Mol Neurobiol. 2014;50:1059-84. https://doi.org/10.1007/s12035014-8705-x.

55. Cavalcanti, et al. Organophosphorous Poisoning: Treatment and Analytical Methodologies Applied in Evaluation of Reactivation and Inhibition of Acetylcholinesterase. Rev Virtual Química. 2016;8:739-66. https://doi.org/10.5 935/1984-6835.20160056.

\section{Publisher's Note}

Springer Nature remains neutral with regard to jurisdictional claims in published maps and institutional affiliations.
Ready to submit your research? Choose BMC and benefit from:

- fast, convenient online submission

- thorough peer review by experienced researchers in your field

- rapid publication on acceptance

- support for research data, including large and complex data types

- gold Open Access which fosters wider collaboration and increased citations

- maximum visibility for your research: over $100 \mathrm{M}$ website views per year

At $\mathrm{BMC}$, research is always in progress.

Learn more biomedcentral.com/submissions 